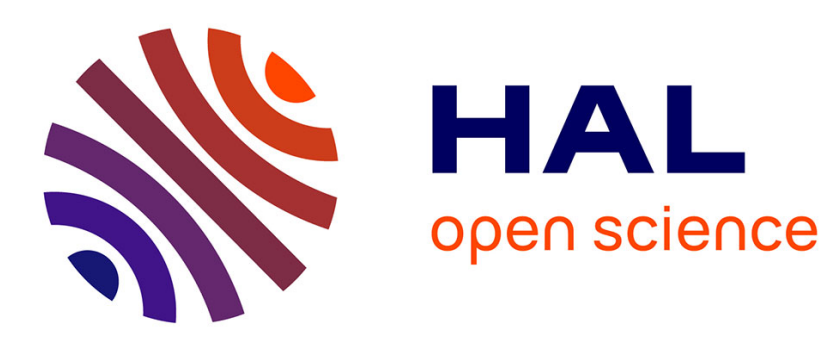

\title{
Health-and-usage-based maintenance policies for a partially observable deteriorating system
}

Estelle Deloux, Mitra Fouladirad, Christophe Bérenguer

\section{To cite this version:}

Estelle Deloux, Mitra Fouladirad, Christophe Bérenguer. Health-and-usage-based maintenance policies for a partially observable deteriorating system. Proceedings of the Institution of Mechanical Engineers, Part O: Journal of Risk and Reliability, 2016, 230 (1), pp.120-129. 10.1177/1748006X15609863 . hal-01397367

\section{HAL Id: hal-01397367 https://hal.science/hal-01397367}

Submitted on 16 Nov 2016

HAL is a multi-disciplinary open access archive for the deposit and dissemination of scientific research documents, whether they are published or not. The documents may come from teaching and research institutions in France or abroad, or from public or private research centers.
L'archive ouverte pluridisciplinaire HAL, est destinée au dépôt et à la diffusion de documents scientifiques de niveau recherche, publiés ou non, émanant des établissements d'enseignement et de recherche français ou étrangers, des laboratoires publics ou privés. 
This papers should be cited as : E. Deloux, M. Fouladirad, C. Berenguer, Health and usage based maintenance policies for a partially observable deteriorating system, Journal of Risk and Reliability - Proceedings of the Institution of Mechanical Engineers, Part $\mathrm{O}$, vol. 230(1), february 2016,pages 120-129 - 10.1177/1748006X15609863

\title{
Health and usage based maintenance policies for a partially observable deteriorating system
}

\author{
Estelle Deloux*, Mitra Fouladirad* ${ }^{*}$, Christophe Bérenguer***** \\ *Université de Technologie de Troyes, Institut Charles Delaunay, UMR CNRS \\ 6281,12 rue Marie Curie, 10010 Troyes, France \\ **Univ. Grenoble Alpes, GIPSA-lab, F-38000 Grenoble, France \\ ***CNRS, GIPSA-lab, F-38000 Grenoble, France
}

\begin{abstract}
The aim of this paper is to discuss the modelling and optimization of condition-based maintenance policies for systems is submitted to usage profile changes. The considered system undergoes a monotone deterioration (gamma process) and its is impacted by the usage conditions (covariates) via the proportional hazards model. Four different policies are proposed and the optimal maintenance parameters minimising the long run average maintenance cost are derived. The different maintenance policies are numerically compared by Monte Carlo simulations.
\end{abstract}

Key words: Condition-based maintenance, Gamma process, usage profile, covariates, long run average maintenance cost.

\section{INTRODUCTION}

This paper focuses on the monitoring and maintenance of a deteriorating system subject to changes in its usage profile. The failure occurs when the deterioration level is higher than an acceptable threshold. The failure is not self declared, i.e. it can be revealed only by inspection. In this framework, the maintenance policy under consideration is a Condition-Based Maintenance (CBM). The CBM considers the current health of the system available through monitoring and based on this latter triggers maintenance operations to avoid failure. The information related to the system health can be collected by continuous monitoring or inspections. This paper considers the case of monitoring by inspections. To avoid a failure occurrence and its consequences a preventive replacement takes place when the system is highly deteriorated. The inspection interval and the deterioration threshold triggering the preventive maintenance 
are the maintenance parameters to be tuned to have a better economic performance of the maintenance policy. For instance, if the inspections are costly, the system is not often inspected. Nevertheless, a low number of inspections leads to a high risk of missing a failure occurence. Therefore, the optimal tuning of the maintenance decision variables one of the main issue in the framework of CBM application. This problem has been addressed intensively, for instance in $[2,14] \mathrm{CBM}$ for a deteriorating system is considered and in $[5,25]$ continuous monitoring replacement policies have been proposed. In these studies a maintenance cost model is proposed which quantifies the costs and benefits of the maintenance strategy and permits to find the optimum balance between monitoring and maintenance efficiency.

In the literature, the problem of condition-based maintenance is mostly focused on monotonically deteriorating systems with static usage profile, $[1,5,12,30,31]$. Since the monitored systems are more often exposed to dynamic environments, the maintenance policies can be improved significantly when the variations, in terms of mission types and operating environments, can be taken into account in the maintenance decision making. These variations can be explained by e.g. various usage profiles or various operation environments for the systems and have a major impact on the degradation behaviour. Disregarding these variations leads to less efficient and somehow non-realistic maintenance policies, [28]. In $[6,16,22,23,24,26,28]$ information on the usage profile is used to plan maintenance operations on a monitored system such as bearings, gear tooth, electronic systems and a high power clutch system. However, taking into consideration these variations requires a prior knowledge on the consequences of different usage profiles on the system degradation.

A large number of works in engineering and life science express the impact of the environmental conditions or the usage profile, called covariates, on the wear or deterioration process. In [17], the author studied the impact of the environmental in usage conditions on the wear process and gives and exact mathematical formulation of the system's properties. In many papers the impact of covariates on the wear is expressed through an exponential model called the proportional hazards model, [27]. If the usage profile is observable it is worthwhile to take benefit of this information in the maintenance policy. In some cases, the usage profile or the environmental conditions monitoring is much cheaper than the health monitoring. For example in the case of wind turbines the wear of the blade is directly related to the wind speed, and more generally to environmental conditions. It could be much easier and cheaper to measure the wind speed and to follow the environmental conditions than performing inspections on the blade of the wind turbine. When the usage profile has a significant impact on the system health or the 
deterioration rate, the maintenance decision rule can be only based on the usage profile, [29]. In this case, a limited number of profiles are identified and a quantitative relation between these usage profiles and the system degradation rate is derived. This kind of classification is often applied in rotorcraft health and usage monitoring systems, where it is called flight regime recognition [15, 21]. In this case, past experience enables the classification of a relative damage severity for each flight regime. By monitoring the usage, both the present health and the remaining life can be estimated. As it is mentioned in [13], for aircraft engines similar algorithms have been also used.

Another alternative when dealing with covariates (usage profile) is to take into account both deterioration and the covariates in the maintenance decision rule. For instance, in the paper [20] the authors address the maintenance of stochastically deteriorating system with covariates. The latter maintenance policy takes into account the covariates but only through their impact on the deterioration process. In $[9,10,34]$ the problem of condition-based maintenance with dynamic environmental conditions is addressed and maintenance decision rules based on both health and covariates are proposed. Inspired by the CBM policies proposed in $[29,34]$ this paper proposes an attempt to analyse thoroughly the CBM problem considering the usage profile (covariates). This paper generalises the results obtained in [11] by proposing a comparison of a health based, usage based and two different health-usage based policies.

The main contributions of this paper are as follows. We propose an original usage-based policy which takes into account the system age and the sojourn time in each usage state. Moreover, a combined health and usage based policy is proposed where in difference with [34] the two indicators (health and covariates) are not necessarily inspected in the same time and the inspection interval for each indicator is optimized separately. Above all, in the cost calculation the usage monitoring cost is also taken into account which makes the total maintenance cost more sensitive to the inspection policy and to the information collected on covariates (usage). For the sake of comparison, we consider two other existing policies in the literature, the four policies are compared and their limits are highlighted and their performances are discussed.

The structure of the paper is as follows. In Section 2, the deterioration model is presented and a stochastic process is proposed to model its evolution. In Section 3 four optimal maintenance decision rules for the system under the consideration are proposed. Eventually, in Section 4 the performances of the proposed maintenance policies are studied through Monte Carlo simulation methods. 


\section{Description of the combined covariates-deterioration model}

\subsection{Deterioration Model}

The system under consideration is observable only through inspections and undergoes an accumulation of damage. The failure occurs when the system is highly damaged i.e., the damage level called deterioration level reaches a pre-determined threshold, say $L$. The threshold $L$ can be seen as a safety level not to be exceeded and the system can be considered as failed even if the system is still functioning. This means that it is no longer able to fulfill its mission in acceptable conditions. Moreover, it is considered that the failure is revealed only by inspection. Let be $X_{t}$ a scalar random ageing variable summarising the state of the system at time $t$. Without maintenance, the time series $\left(X_{t}\right)_{t \geq 0}$ is an increasing stochastic process, with initial state $X_{0}=0$. In $[4,19]$, authors model the increasing deterioration by a Gamma process considering environmental changes. The Gamma process is very suitable to model monotone deteriorations and it has been widely applied to model condition-based maintenance, see [30]. Hereafter, it is supposed that for all $0 \leq s<t$, the increments of $\left(X_{t}\right)_{t \geq 0}$ between $s$ and $t$, $Y_{t-s}=X_{t}-X_{s}$, follow a gamma probability density function with shape parameter $\alpha \in \mathbb{R}^{+} \backslash\{0\}$ and scale parameter $\beta \in \mathbb{R}^{+} \backslash\{0\}$ defined as follows:

$$
f_{\alpha \cdot(t-s), \beta}(y)=\frac{y^{\alpha \cdot(t-s)-1} e^{-\frac{y}{\beta}}}{\Gamma(\alpha \cdot(t-s)) \beta^{\alpha \cdot(t-s)}} \mathbb{1}_{\{y \geq 0\}}
$$

where $\mathbb{1}_{\{y \geq 0\}}=1$ if $y \geq 0$ and $\mathbb{1}_{\{y \geq 0\}}=0$ otherwise.

In this framework, $\mathbb{E}\left(Y_{t-s}\right)=\alpha \cdot(t-s) \beta$ is the average deterioration rate during the time $t-s$ and $\operatorname{var}\left(Y_{t-s}\right)=\alpha \cdot(t-s) \beta^{2}$. By varying the parameters $\alpha$ and $\beta$ one can model various deterioration behaviours.

\subsection{Impact of the usage on the deterioration}

We consider a set of $m$ usage profiles. The usage profile at time $t$ is presented by a random variable denoted by $Z_{t}$. It is sensible to consider that the usage profile can change during a mission and switch from a state to another. Through historical data, experience or expert judgement the transition probabilities from one state to another can be estimated. It is also plausible to consider the transition to a new profile depends only on the last usage profile (state) since these states change slowly comparatively to the system life cycle. Therefore, similarly to [17], the time series $Z=\left\{Z_{t}, t \geq 0\right\}$ is supposed to be a homogeneous Markov chain with finite state space $\{1,2, \cdots, m\}$ which describes the different usage 

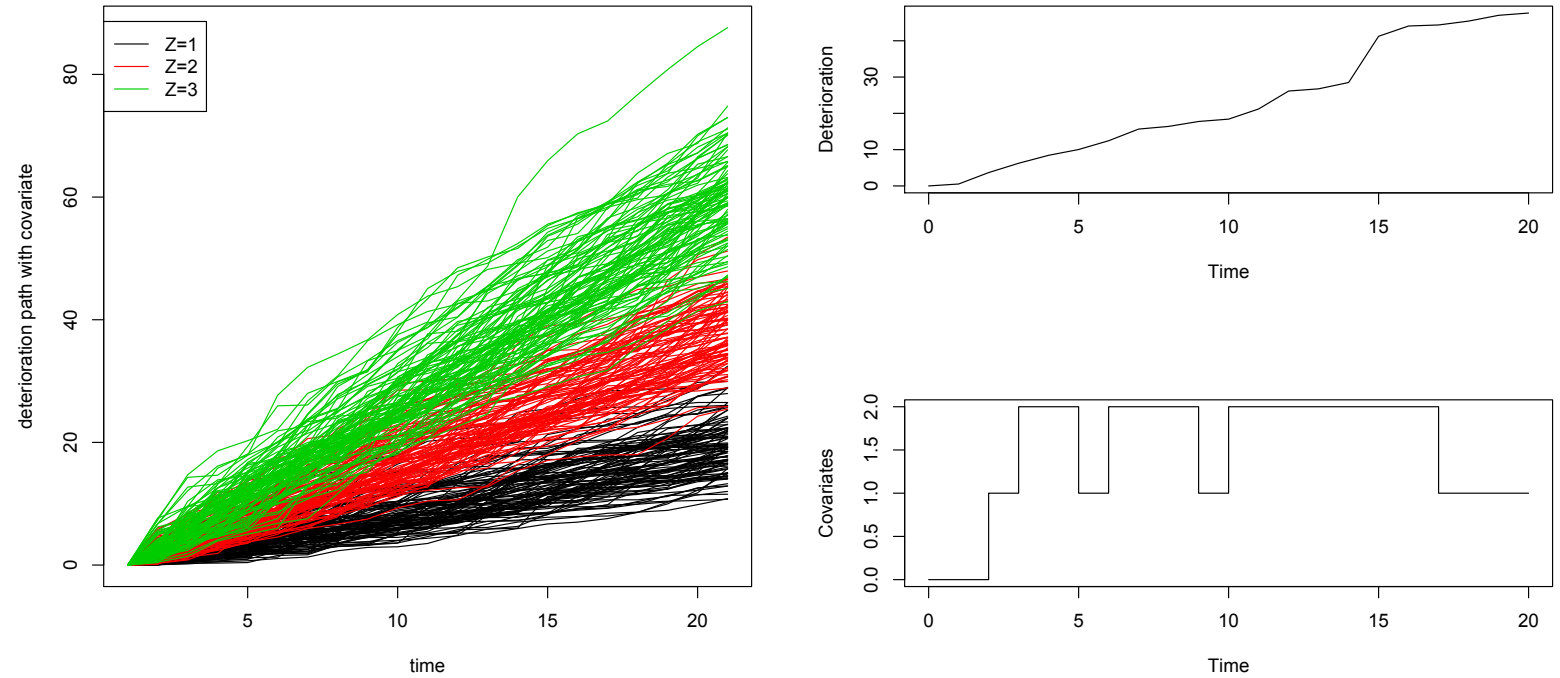

Figure 1: The deterioration with fixed usage profile (3 possible usage profile) (Left). The deterioration subject to usage profile changes (Right).

profiles. The usage profiles are observable only by inspections. One denotes by

$$
p_{i j}(t-s)=P\left(Z_{t}=j \mid Z_{s}=i\right), \quad t>s,
$$

the transition probabilities of the chain $Z$ during $t-s$. It is supposed that the system usage impacts the system deterioration through the shape function $\alpha$. Let us denote by $t=t_{n}(n \in \mathbb{N})$ the unit time series. We shall denote by $X_{t_{n}}\left(Z_{t_{n}}\right)$ the observed process at time $t_{n}$, for $n \geq 1$, depending on $Z_{t_{n}}$, where given $Z_{t_{n}}$ and $Z_{t_{n-1}}, X_{t_{n}}\left(Z_{t_{n}}\right) \sim \Gamma\left(\alpha\left(Z_{t_{n}}\right), \beta\right)$ and the increments $X_{t_{n}}\left(Z_{t_{n}}\right)-X_{t_{n-1}}\left(Z_{t_{n-1}}\right)$ are independent.

More thoroughly, the impact of the usage profile $Z_{t_{n}}=z_{t_{n}}$ on $X_{t_{n}}$, is described by the proportional hazards model proposed by $[8]$ as follows:

$$
\alpha\left(z_{t_{n}}\right)=a \exp \left(b_{1} \mathbb{1}_{\left(z_{t_{n}}=1\right)}+\cdots+b_{m} \mathbb{1}_{\left(z_{t_{n}}=m\right)}\right),
$$

where $a \in \mathbb{R}$ and $b=\left(b_{1}, b_{2}, \cdots, b_{m}\right)$ is the vector of regression parameters. We assume that $b_{1} \leq b_{2} \leq$ $\ldots \leq b_{m}$.

An example of a deterioration phenomenon impacted by the usage profile is depicted in Figure 1.

\section{Maintenance decision rule}

In this section, four different maintenance policies are proposed considering the following assumptions: 
- The system health and the usage profile are observed only through inspections.

- The inspections are periodic.

- The inspections are perfect i.e., they reveal the true state of the system and the usage profile.

- The replacements are instantaneous and they can be carried out only at inspection times.

- Only two maintenance actions are possible, which are preventive replacement and corrective replacement.

- The usage profile is not impacted by the maintenance actions.

In summary, after a replacement the system is as good as new $\left(X_{0}=0\right)$ and the usage profiles $Z_{t_{n}}$ is not impacted. The failure occurs at the first hitting time of the threshold $\mathrm{L}$

$$
G_{L}=\inf \left\{t \in R^{+}: X_{t}\left(Z_{t}\right) \geq L \mid X_{0}=0\right\} .
$$

At time $G_{L}$ the system is correctively replaced.

Consider the 4 following maintenance policies :

- Health Based Maintenance (HBM)

- Usage Based Maintenance (UBM)

- two Health and Usage Based Maintenances

- one with unique and common inspection policy for the both deterioration and the usage (HUBM 1)

- one with different inspection policies for the deterioration and the usage (HUBM 2)

The health based policy (HBM) takes into account only the deterioration level and ignores the usage profile in the decision rule. The usage based policy (UBM) takes into account the usage profile and ignores the deterioration level in the decision rule. Health and usage based policies (HUBM1 \& HUBM2) take into account the usage profile as well as the deterioration level in the decision rule. These policies are summed up in the following paragraphs. Throughout this paper, we consider $x_{t}$ the observed value of $X_{t}$ at time $t$. 


\subsection{Health Based Maintenance (HBM)}

In the framework of the HBM a unique preventive threshold $L_{p}\left(L_{p}<L\right)$ is considered. The system is inspected periodically each $\tau$ time units. Let be $\left(T_{n}\right)_{n \in \mathbb{N}}$ the inspection time series where $T_{n}=n \tau$. At the inspection time $T_{n}$ the following events can occur:

- if $x_{T_{n}} \geq L$ the system is correctively replaced.

- if $L_{p} \leq x_{T_{n}} \leq L$ the system is preventively replaced.

- otherwise the decision is postponed until the next inspection at time $(n+1) \tau$.

\subsection{Usage Based Maintenance (UBM)}

In the UBM the maintenance decision rule ignores the real deterioration level of the system but it is assumed the impact of the environment changes on the deterioration process speed is known. Such a policy could be risky in sense that the overtaking of the failure threshold can be missed and cause harmful consequences. To overcome this problem, the decision parameters of usage profile based maintenance policy should be carefully chosen in order to reduce the risk of a failure occurrence. Moreover, in this paper we consider that the usage conditions change very slowly. The proposed UBM is based on the usage profile and the sojourn time in each state.

To implement a UBM policy, we propose a heuristic policy consisting of two main stages: an offline step determining the optimal age replacement associated to each usage profile, and an online step adapting the replacement age to the observed usage profile of the maintained system. The dynamic updating of the replacement age is made according to an heuristic rule described below. The UBM policy can be summarized as follows

The system is inspected periodically and let $\tau$ be the inspection interval. Assume that the following assumptions are satisfied:

- between two inspections there is maximum two usage profile changes.

- to go from state $i$ to $i+2$ the usage profile goes for sure through state $i+1$.

To implement the UBM policy the following steps are required: 
1. First we consider an age replacement policy for each usage profile $i \in\{1, \ldots, m\}$, and therefore, a replacement age is associated to each usage profile. Let be $A_{i}$ the replacement age when $Z_{t_{n}}=i$ for all $n \in \mathbb{N}$.

2. At the inspection time $T_{n}=n \tau$, according to the observed usage profile, denoted $z_{T_{n}}$ and the sojourn time in each state until $T_{n}$, a replacement time $\varrho(n)$ is calculated. The replacement time $\varrho(n)$ is a mean of different replacement ages $A_{i}$ weighted by the sojourn time in each state. $\varrho(n)$ is recursively calculated to adapt sequentially the replacement time to the operational conditions.

At the inspection time $T_{n}$ the following events can occur:

- according to the value of $z_{n}$ the replacement of the system is planned for $\varrho(n)$.

- if $\varrho(n) \leq T_{n}$ the system is immediately replaced at $T_{n}$,

- if $T_{n}<\varrho(n) \leq T_{n}+\tau$ the system is replaced at $\varrho(n)$

- otherwise the decision is revised at the next inspection in $T_{n+1}=T_{n}+\tau$.

Replacement time recursive calculation. When only three usage profiles are considered, $m=3$. This case is only an example for which numerical computations are possible. $\varrho(n)$ is recursively computed as follows:

- if no change of usage profile is observed at the two consecutive inspection times $T_{n-1}$ and $T_{n}$, i.e. $z_{T_{n}}=z_{T_{n-1}}$, it is possible to have a change of state between the two inspections. Since the continuous monitoring is not applied, the sojourn time in this intermediate state is unknown and less than $\tau$. In this case, $\varrho(n)$ is calculated as the weighted mean of the last calculated replacement time $\varrho(n-1)$ and the replacement age corresponding to $z_{T_{n}}, z_{T_{n}}+1$ and $z_{T_{n}}-1$, denoted respectively by $A_{z_{T_{n}}}, A_{z_{T_{n}}+1}$ and $A_{z_{T_{n}}-1}$.

- If a change of profile is observed between the two consecutive inspection times, there are two possible cases: $\left|z_{T_{n}}-z_{T_{n-1}}\right|=1$ and $\left|z_{T_{n}}-z_{T_{n-1}}\right|=2$.

- In the case $\left|z_{T_{n}}-z_{T_{n-1}}\right|=1,\left(z_{T_{n}}, z_{T_{n-1}}\right) \in\{(1,2),(2,1),(2,3),(3,2)\}$ and since, by assumption, to go from state $i$ to $i+2$ the usage profile goes for sure through state $i+1$, there is no change of profile between the two inspections. 
- In the case $\left|z_{T_{n}}-z_{T_{n-1}}\right|=2,\left(z_{T_{n}}, z_{T_{n-1}}\right) \in\{(1,3),(3,1)\}$ and the usage profile goes, for sure, through state 2 between the two inspections.

In both cases, the replacement time of the system $\varrho(n)$, is a weighted sum of $A_{i}, i \in\{1, \ldots, 3\}$ according to the time spent in each state until $T_{n}$.

More precisely, $\varrho(n)$ is recursively calculated as follows:

$$
\begin{aligned}
& \varrho(n)=\mathbb{1}_{\left\{z_{T_{n}}=z_{T_{n-1}}\right\}} \frac{1}{n} \int_{0}^{\tau} \int_{0}^{\tau-t} p_{z_{T_{n}} z_{T_{n}}}(t) A_{z_{T_{n}}}+p_{z_{T_{n}} z_{T_{n}}-1}(s) A_{z_{T_{n}}-1}+p_{z_{T_{n}} z_{T_{n}}+1}(s) A_{z_{T_{n}}+1} d s d t+\frac{(n-1) \varrho(n-1)}{n} \\
& +\mathbb{1}_{\left\{\left|z_{T_{n}}-z_{T_{n-1}}\right|=1\right\}} \frac{1}{T_{n}}\left[T_{n-1} \varrho(n-1)+\int_{1}^{\tau} s p_{z_{T_{n-1}} z_{T_{n}}}(s-1) A_{z_{T_{n-1}}}+(\tau-s)\left(1-p_{z_{T_{n-1}} z_{T_{n}}}(s-1)\right) A_{z_{T_{n}}} d s\right] \\
& +\mathbb{1}_{\left\{\left|z_{T_{n}}-z_{T_{n-1}}\right|=2\right\}} \frac{1}{T_{n}}\left[T_{n-1} \varrho(n-1)+\int_{1}^{\tau-1} \int_{s+1}^{\tau} u p_{z_{T_{n-1}} 1}(u-1) A_{z_{T_{n-1}}}+s p_{1 z_{T_{n}}}(s-1) A_{1}\right) \\
& +A_{z_{T_{n}}}\left(\tau-s\left(1-p_{z_{T_{n-1}}}(u-1)-p_{1 z_{T_{n}}}(s-1)\right) d u d s\right]
\end{aligned}
$$

where for the event $A, \mathbb{1}_{A}=1$ if $A$ is true, otherwise $\mathbb{1}_{A}=0$.

\subsection{Health and Usage Based Maintenances}

In this section two different health and usage based policies are considered. The first health and usage based policy is similar to the adaptive policy proposed in $[11,34]$ in the sense that the health and the usage information are collected at the same time. Whereas, in the second policy the health and the usage information are available at different inspection times. The second policy is more sophisticated, requires more parameters to optimize and permits separate monitorings of the usage profile and of the deterioration.

\subsubsection{Health and Usage Based Maintenance 1 (HUBM1)}

In the framework of the HUBM1 policy, a preventive threshold $L_{p_{i}}$ and an inspection period $\tau_{i}$ are associated to each usage profile $i, 1 \leq i \leq m$, which means that at the inspection time $T_{n}$ according to the observed usage profile, the preventive threshold and the inspection interval are readjusted. In this policy at the inspection time $T_{n}$ the following events can occur:

- if $x_{T_{n}} \geq L$ the system is correctively replaced, 
- if $z_{n}=i$

- if $L_{p_{i}} \leq x_{T_{n}} \leq L$ the system is preventively replaced and the next inspection is scheduled for $T_{n+1}=(n+1) \tau_{i}$

- otherwise the decision is postponed until the next inspection at $T_{n+1}=(n+1) \tau_{i}$.

\subsubsection{Health and Usage Based Maintenance 2 (HUBM2)}

In the framework of the HUBM2 policy, a preventive threshold $L_{p_{i}}$ and a deterioration inspection period $\tau_{i}$ are associated to each usage profile $i, 1 \leq i \leq m$. Furthermore, a different inspection period $\tau_{c o}$ is associated to the usage profile. The preventive threshold and deterioration inspection period could only change at the usage inspection times. These parameters are readjusted only if during a usage inspection a change of profile is observed. The maintenance decision will take place only during the deterioration inspections $\left(T_{n}\right)_{n \in \mathbb{N}}$. Let be $\lfloor x\rfloor$ the integer part of the real number $x$. In this policy at the inspection time $T_{n}$ the following events can occur:

- if $x_{T_{n}} \geq L$ the system is correctively replaced,

- if $z_{\left\lfloor\frac{T_{n}}{\tau_{c o}}\right\rfloor \tau_{c o}}=i$,

- if $L_{p_{i}} \leq x_{T_{n}} \leq L$ the system is preventively replaced and the next deterioration inspection is scheduled at $T_{n+1}=(n+1) \tau_{i}$,

- otherwise the decision is postponed until the next inspection at $T_{n+1}=(n+1) \tau_{i}$.

The four policies are summarized in Table 1.

\begin{tabular}{|c|c|c|c|}
\hline $\begin{array}{c}\text { Maintenance } \\
\text { Policy }\end{array}$ & $\begin{array}{c}\text { decision } \\
\text { indicator }\end{array}$ & $\begin{array}{c}\text { decision } \\
\text { parameters }\end{array}$ & $\begin{array}{c}\text { preventive } \\
\text { replacement }\end{array}$ \\
\hline HBM & deterioration level $x_{t}$ & $\left(L_{p}, \tau\right)$ & $x_{T_{n}}>L_{p}$ \\
\hline UBM & usage based replacement time $\varrho(n)$ & $\tau$ & $\varrho(n) \in\left\{0, T_{n}+\tau\right\}$ \\
\hline HUBM1 & deterioration and usage $\left(x_{t}, z_{t}\right)$ & $L_{p_{i}}, \tau_{i}, i \in\{1, \cdots, n\}$ & $x_{T_{n}}>L_{p_{i}}$ if $z_{T_{n}}=i$ \\
\hline HUBM2 & deterioration and usage $\left(x_{t}, z_{t}\right)$ & $L_{p_{i}}, \tau_{i}, i \in\{1, \cdots, n\}, \tau_{c o}$ & $x_{T_{n}}>L_{p_{i}}$ if $z_{\left[\frac{T_{n}}{\tau_{c o}}\right] \tau_{c o}}=i$ \\
\hline
\end{tabular}

Table 1: A summary of the four maintenance policies 


\subsection{Maintenance policy evaluation}

The implementation of a maintenance action on the system implies a cost. A cost $C_{c}$ (respectively $C_{p}$ ) is associated to each corrective (respectively preventive) replacement. It is supposed that $C_{p}<C_{c}$ since the corrective replacement is generally more complex and more expensive. Each deterioration inspection (respectively usage profile inspection) entails the cost $C_{i_{x}}$ (respectively $C_{i_{c}}$ ). Let be $C_{i}=\mathbb{1}_{\text {deterioration inspection }} C_{i_{x}}+\mathbb{1}_{\text {usage inspection }} C_{i_{c}}$. During the time spent by the system in a failed state (unavailability period) the cost $C_{u}$ per unit of time is incurred. The maintenance policy is evaluated using a long run average cost considering each maintenance actions cost. Let $N_{p}(t)$ be the number of preventive replacements before $t, N_{c}(t)$ the number of corrective replacements before $t, d_{u}(t)$ the cumulative unavailability duration of the system before $t$ and $N_{i}(t)$ the number of inspections before $t$. Recall that $N_{i}(t)=\left\lfloor\frac{t}{\tau}\right\rfloor$ where $\lfloor x\rfloor$ denotes the integer part of the real number $x$. Let $T$ be the length of a life-time cycle, i.e. between two replacements, and as mentioned before $G_{L}$ the random time at which the system state exceeds threshold $L$. The property of the regeneration process $\left(X_{t}\right)_{t \geq 0}($ see $[3])$ allows us to write:

$$
C_{\infty}=\lim _{t \rightarrow \infty} \frac{\mathbb{E}(C(t))}{t}=\frac{\mathbb{E}(C(T))}{\mathbb{E}(T)}
$$

where

$$
C(t)=C_{i} N_{i}(t)+C_{p} N_{p}(t)+C_{c} N_{c}(t)+C_{u} d_{u}(t)
$$

and

$$
\mathbb{E}\left(d_{u}(t)\right)=\mathbb{E}\left(T-G_{L}\right) \mathbb{1}_{\left\{G_{L}<t\right\}}
$$

\subsection{Maintenance optimization}

\subsubsection{Health Based maintenance policy}

In the framework of the HBM policy the optimisation problem is therefore to chose the value of $L_{p}^{*}$, $\tau^{*}$ that minimise the expected long-run average maintenance cost as follows:

$$
\left(L_{p}^{*}, \tau^{*}\right)=\arg \min _{\left(L_{p}, \tau\right)} C_{\infty}
$$

\subsubsection{Usage Based Maintenance policy}

In the case of an UBM the decision parameters are as follows: $\tau$ and $\left(A_{1}, \cdots, A_{m}\right)$. The multidimensional optimisation is a difficult task to implement. To bypass this difficulty, the problem is treated 
separately for each usage profile. For each $i \in\{1, \ldots, m\}$ the optimal $A_{i}^{*}$ which minimises $E C_{\infty}(Z=i)$ is calculated. The inspection period is defined as follows:

$$
\tau^{*}=\arg \min _{\tau} C_{\infty}
$$

where $\left(A_{1}^{*}, \cdots, A_{m}^{*}\right)$ is the actual replacement age vector. This separate optimisation reduces significantly the calculation time but the price to pay is to lose the optimality of the solution which can be obtained only by a multi-dimensional optimisation.

\subsubsection{Health and Usage Maintenance 1}

In the case of the HUM1 policy the decision parameters are as follows:

$$
L_{p}=\left(L_{p, 1}, \cdots, L_{p, m}\right), \quad \tau=\left(\tau_{1}, \cdots, \tau_{m}\right)
$$

Since $L_{p} \in \mathbb{R}^{m}, \tau \in \mathbb{R}^{m}$ the multi-dimensional optimisation is a difficult task to implement. To reduce the calculation time by accepting to lose the optimality, which can be obtained only by multi-dimensional optimisation, the decision parameters are optimised for each usage profile. In other words when $Z_{n}=i$ for $n \in \mathbb{N}$, the following decision parameters are defined:

$$
\left(L_{p, i}^{*}, \tau_{i}^{*}\right)=\arg \min _{\left(L_{p, i}, \tau_{i}\right)} C_{\infty}(Z=i)
$$

At the inspection time $T_{n}$, if $z_{T_{n}}=i$ the maintenance decision parameters are switched to the one corresponding to $Z=i$ and the parameters $\left(L_{p, i}^{*}, \tau_{i}^{*}\right)$ become the actual maintenance decision parameters until the next inspection at $T_{n+1}$.

\subsubsection{Health and Usage maintenance 2}

In the case of the HUM2 policy the decision parameters are as follows:

$$
L_{p}=\left(L_{p, 1}, \cdots, L_{p, m}\right), \quad \tau=\left(\tau_{1}, \cdots, \tau_{m}\right), \text { and } \tau_{c o}
$$

Similarly to the adaptive maintenance policy 1 , the decision parameters $L_{p}=\left(L_{p, 1}, \cdots, L_{p, m}\right)$ and $\tau=\left(\tau_{1}, \cdots, \tau_{m}\right)$ are optimised for each usage profile. The last parameter $\tau_{c o}$ is defined as follows:

$$
\tau_{c o}^{*}=\arg \min _{\tau_{c o}} C_{\infty}
$$

where $\left(L_{p, 1}^{*}, \cdots, L_{p, m}^{*}\right)$ and $\left(\tau_{1}^{*}, \cdots, \tau_{m}^{*}\right)$ are effective vector parameters. 
Therefore, the usage profile is inspected periodically each $\tau_{c o}^{*}$ time units and the system is inspected at inspection times $\left(T_{n}\right)_{n \in \mathbb{N}}$. At the inspection time $T_{n}$ if $z_{\left[\frac{T_{n}}{\tau_{\tau o}^{*}}\right] \tau_{c o}^{*}}=i$ the maintenance decision parameters are switched to the one corresponding to $Z=i$ and the parameters $\left(L_{p, i}^{*}, \tau_{i}^{*}\right)$ become the actual maintenance decision parameters until the next inspection at $T_{n+1}=T_{n}+\tau_{i}^{*}$.

\section{Numerical example}

For the comparison of the four maintenance policies, it is instructive to change the properties of the usage profile and to analyse the influence of these changes on the performance of the four policies. In this purpose, consider a deteriorating system where the usage profile process $Z$ is a 3 -state Markov chain with value in $\{1,2,3\}$, with a parametrized transition matrix

$$
P_{\alpha}=\left(\begin{array}{ccc}
1-\lambda & \lambda & 0.00 \\
\lambda / 2 & 1-\lambda & \lambda / 2 \\
0.00 & \lambda & 1-\lambda
\end{array}\right),
$$

where $\lambda \in[0,1]$ and initial state $Z_{0}=1$. The regression parameters $b_{1}, b_{2}, b_{3}$ and the parameter $\alpha$ in Equation (2) are chosen such that the shape function has the following values: $\alpha(1)=1, \alpha(2)=2$ and $\alpha(3)=3$. The scale parameter $\beta=1$ for all $Z_{n} \in\{1,2,3\}, n \in \mathbb{N}$. It is supposed that $C_{c}=100, C_{p}=20$, $C_{u}=30$. The value $C_{i}$ is varied in order to analyse the influence of this cost on each maintenance cost policy. The failure threshold is set to $L=20$.

Since the replacement has no impact on the usage profile, the renewal property cannot be used for the close form cost calculation. However, due to the markovien property of the deterioration and the usage profile, it is possible to calculate the average cost between two inspections (the semi-regenerative property [3]). In this aim, the invariant distribution of the chain $\left(X_{t}, Z_{t}\right)_{t \geq 0}$ should be derived and the average cost optimised [3]. Even for the simple case of a three state slow usage profile, the cost calculation and optimisation is very difficult. This is due to the recursive form of the replacement period in the case of the UBM policy and due to separate inspection intervals for usage profile and the deterioration in the HUM2 policy. Hence, in order to have a better comparison of the four policies and be able to study the impact of unit cost variations, Monte Carlo simulations methods are used to derive the optimal maintenance policies. The following results are obtained by using Monte Carlo simulations considering a sufficiently large number of simulation such that the long-run cost rate is convergent. 


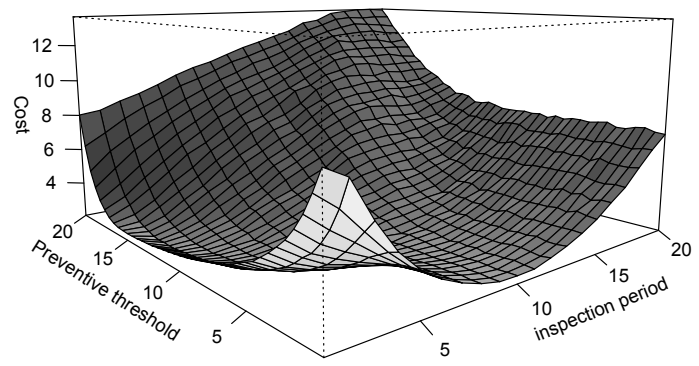

Figure 2: Cost evolution of the health based maintenance according to $L_{p}$ and $\tau$

Figure 2 shows the expected cost rate of the Health-Based Maintenance policy for the following maintenance costs $C_{c}=100, C_{p}=20, C_{u}=30, C_{i x}=0.9$ and $\lambda=0.05$. It can be seen that optimal decision parameters are $L_{p}=12.5$ and $\tau=3$ with an optimal cost rate $C_{\infty}=2.07$ monetary units.

In Figure 3 the impact of the inspection cost on the optimal long run average maintenance costs of the four policies is illustrated. The total inspection $\operatorname{cost} C_{i}$ is fixed to 1 on Figure 3 (left) and to 5 on Figure 3 (right). The impact of the $C_{i_{c}}=C_{i}-C_{i_{x}}$ variation over the optimal long run average maintenance cost is studied. It means that in Figure 3 (left) $C_{i_{x}} \in[0,1]$ and $C_{i_{c}} \in[0,1]$ such that $C_{i_{x}}+C_{i_{c}}=1$ and in Figure 3 (right) $C_{i_{x}} \in[0,5]$ and $C_{i_{c}} \in[0,5]$ such that $C_{i_{x}}+C_{i_{c}}=5$. It is supposed that $\lambda=0.01$ where the usage profile changes slowly. It can be noticed in Figure 3 (left):

- the Health Usage Based Maintenance 2 (HUBM2) policy is the most efficient policy whatever the inspection costs.

- the efficiency of the HUBM1 policy depends on the values of $C_{i_{x}}$ and $C_{i_{c}}$. When $C_{i c}$ increase and become greater than $C_{i x}$ the long run average cost is impacted and increases.

- the cost of the HBM is directly impacted by the value of $C_{i x}$. When $C_{i c}$ increases $C_{i x}$ decreases and the long run average cost of the HBM decreases. 

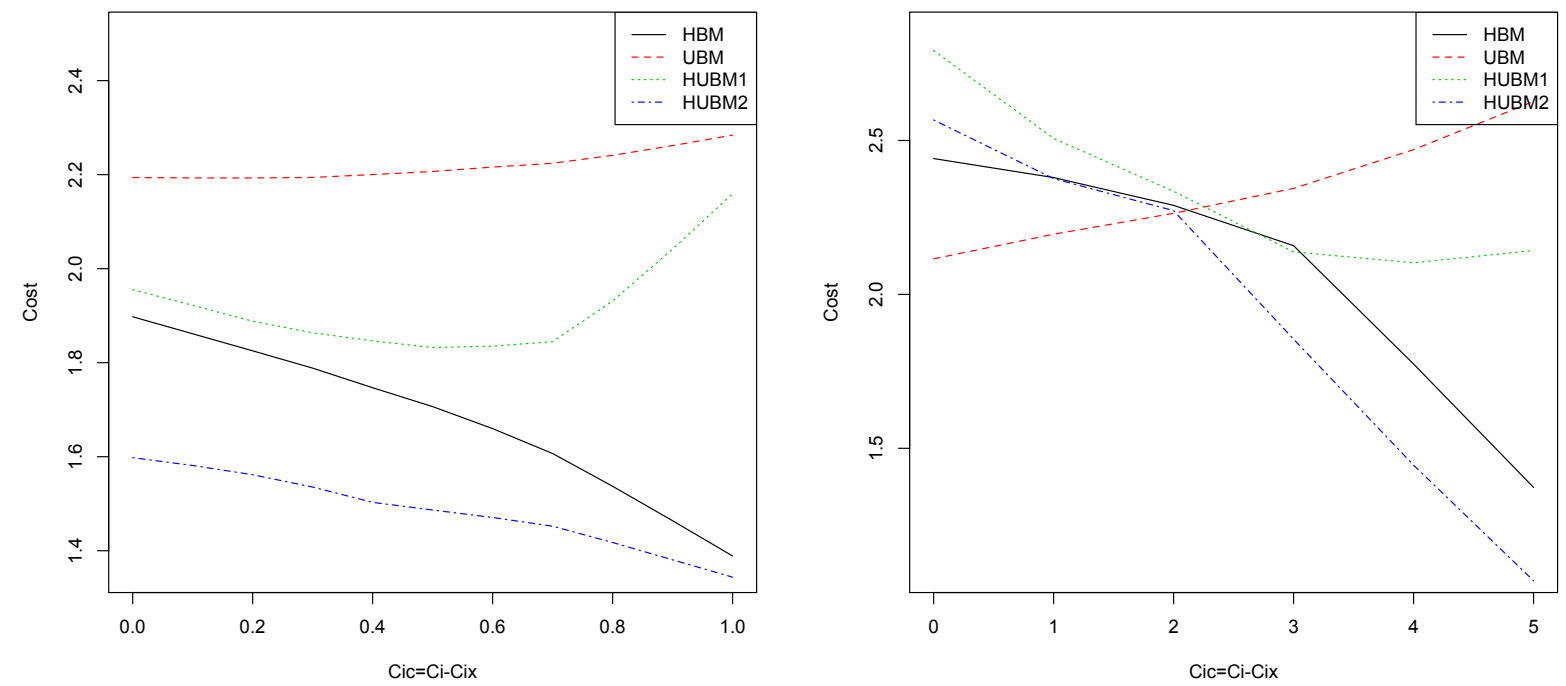

Figure 3: The influence of the inspection cost when $C_{i}=1$ (left) and when $C_{i}=5$ (right).

- when $C_{i}=1$ the Usage Based Maintenance (UBM) is not efficient because in this case the deterioration inspection cost is low and thus the most efficient policy is based on all the available information.

In Figure 3 (right), it can observed that when the usage profile monitoring cost is low compared to the deterioration inspection cost $\left(C_{i c}\right.$ between 0 and 2) the Usage Based Maintenance (UBM) is cheaper than the other policies. When $C_{i c}$ increases (between 2 and 5) the advantage of health monitoring takes over and the cost corresponding to the three policies, HBM, HUBM1, HUBM2 decrease.

According to Figure 3 the advantage of each of the policies over the others varies with the inspection cost variations therefore a more specific comparison of these policies is carried out in the following paragraphs in order to complete results obtained in [11]. In [11] a first comparison of the the HBM, HUM1 and UBM policies is carried out and it induces that to study the behaviour of the optimal long run average maintenance costs it is not conceivable to ignore the profile change frequency controlled by the parameter $\lambda$ :

- when the usage monitoring cost is 0.1 and when the usage profile changes very slowly $(\lambda<0.02)$, Figure 4 (left), all the policies perform better than the HBM policy. In other words, when the sojourn time of usage profile in each state is very long and the $C_{i c}$ is rather cheaper than $C_{i x}$, it 

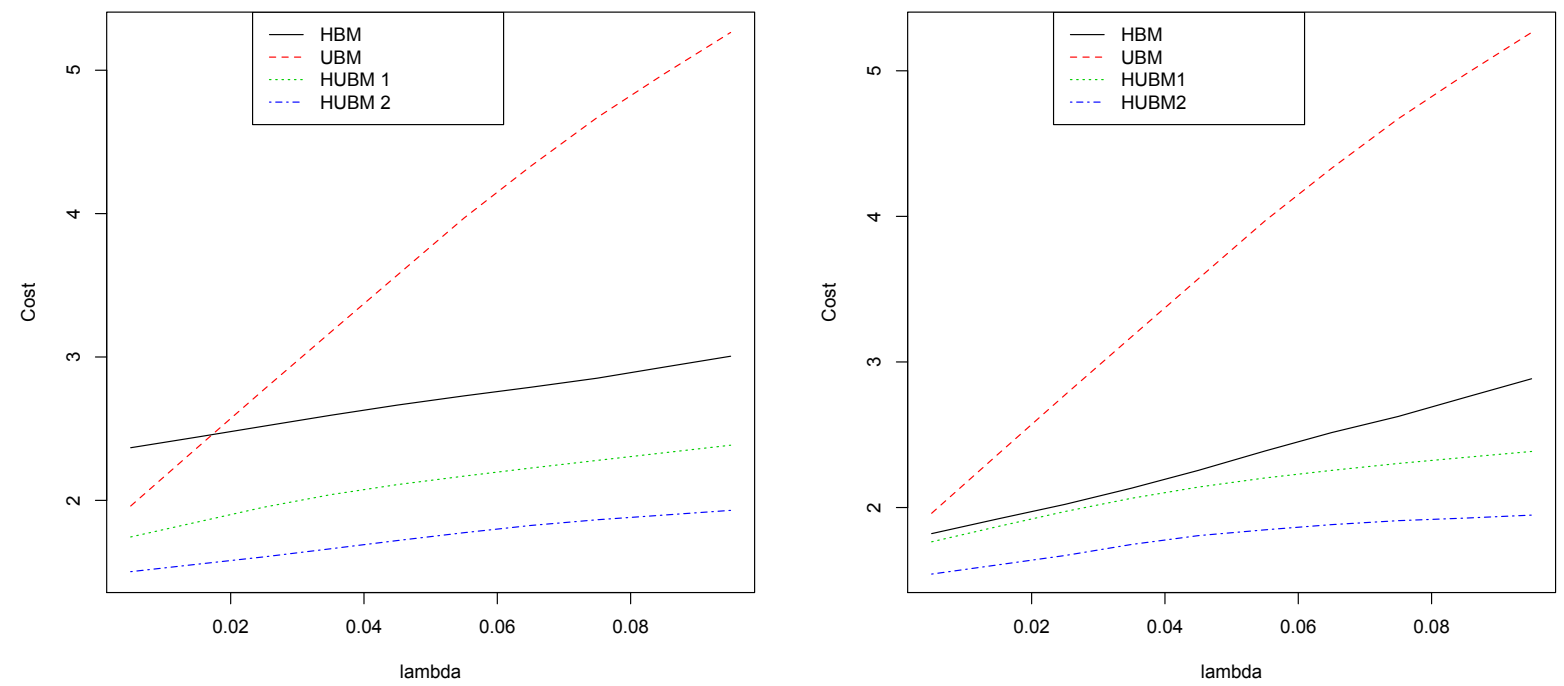

Figure 4: Optimal long run average costs for the four policies as a function of $\lambda$ when $C_{i c}=0.1\left(C_{i}=1\right)$ (left) and $C_{i c}=0.05\left(C_{i}=1\right)$ (right).

seems natural to use a policy not ignoring the usage profile.

- when the usage monitoring cost is high $\left(C_{i c}=0.5\right.$, Figure 4 (right) $)$ the UBM is no more competitive.

The obtained results imply that the behaviour of the four policies are not always the same and for the same $C_{i c}$ it depends strongly on the sojourn time of usage profile in each state. The longer the usage profile stays in a state better it translates the deterioration and more efficient is the usage based maintenance. But in case that usage profile changes state very fast the usage based maintenance is not efficient anymore since the observed state at the inspection time does not indicate the usage profile between two inspections. In this framework, as the inspection cost $C_{i c}$ grows the performance of the health and usage based policy takes over.

Hence it can be pointed out that the advantage of each policy depends on the usage profile inspection cost and its sojourn time in each state. However the HUBM2 seems to be always the most efficient for the studied configuration.

The proposed policies could be applied to real industrial problems. However, the most difficult 
task in real life maintenance systems is to have a deterioration indicator in our disposal. Mostly, this indicator should be extracted from multivariate health indicators or be built using available data, see [18]. Once the deterioration indicator is available, in real life problems the impact of the environment (usage) on the deterioration should be estimated, for example through the estimation of the Cox model parameters. Another difficulty in real life maintenance problems is the fact that the indicators are not directly observable. Dealing with imperfect observations is beyond the scope of this paper and one can refer to the conclusion for more explanations. When all information is available, the maintenance policies proposed in this paper can be implemented and an off-line optimisation procedure carried out.

\section{CONCLUSION}

In this paper a monotone deteriorating system influenced by usage profile of the system is considered. The main interests of this work is the development of maintenance policies based not only on the deterioration level but also on the usage profile. Four different maintenance decision rules which differ on the monitoring variable - health based policy, usage based policy and two health and usage based policies - are proposed and their performances are analyzed. For different cost values and usage profiles evolutions the efficiency of the different policies is investigated. Each of the four policies could take over the advantage and efficiency depending on the parameters under consideration.

In this paper, it is considered that the usage only impacts the shape function of the Gamma process (parameter alpha). This hypothesis is motivated by the fact that the behavior of the degradation is resumed by the shape function and the changes in beta have only a scaling impact which variations do not change fundamentally the deterioration behavior. This hypothesis simplifies the model and makes the calculations and maintenance policy optimisation more tractable. This choice is not exclusive and the results can be extended to the case where the scale parameters is also impacted by the covariates. If real data is available and no prior knowledge on the model is in our disposal, the fact that environmental changes can impact the scale parameter should not be discarded.

Even though the proposed structure for maintenance decisions has shown interesting performances, much research work remains to be done.

The optimal usage based maintenance policy is difficult and very time consuming to be carried

out. This difficulty is bypassed by proposing a suboptimal policy where separate decision parameters optimisations are carried out. Since the optimal solution is not implemented, the gap between the optimal 
policy and the suboptimal solution is not estimated. This gap estimation can evaluate the quality of the proposed suboptimal solutions. The optimal solution obtention in reasonable time requires specific efficient algorithms. In the immediate future works this problem should be addressed in order to be capable to bring out the interest of the suboptimal solution.

In practice, the Cox model parameters are usually unknown. In addition to a estimation step a sensitivity analysis should be performed to study the impact of the modeling hypotheses and estimation method on the maintenance policies.

In this work, we have assumed that the monitoring of the deterioration and of the usage profile is perfect. A future extension of this work could be also to consider that the monitoring is imperfect. If the monitoring is not perfect the maintenance policy should be driven accordingly. To deal with imperfect observations one alternative is to implement a filtering method to estimate the real health or usage indicator. For instance, methods applied to Hidden Markov Models can be used. The filtering method induces estimation errors which impact subsequently the maintenance decision rule based on the estimated values. A sensitivity analysis of such error on the maintenance decision rule should be carried out. Another alternative is to propose a symptom-based maintenance policy which could be more suitable to imperfect observations. In such framework, the decision is based directly on the imperfect observations and no filtering step is implemented. Aware of the quality of the observations and the fact that the decision is based on a symptom and not a real indicator, the decision parameters are carefully chosen. The two policies should be compared and discussed.

\section{References}

[1] Abdel-Hameed, M. (1975). A gamma wear process. IEEE Transaction on Reliability 24(2), 152-153.

[2] Abdel-Hameed, M. (1987). Inspection and maintenance policies of devices subject to deterioration. Advances in applied probability 19(4), 917-931.

[3] Asmussen, S., 2003. Applied Probability and Queues - 2nd edition,Springer.

[4] Bagdonavičius, V., Nikulin, M., 2000. Estimation in degradation models with explanatory variables. Lifetime Data Analysis 7 (1), 85-103.

[5] Bérenguer, C., Grall, A., Dieulle, L., Roussignol, M., 2003. Maintenance policy for a continuously 
monitored deteriorating system. Probability in the Engineering and Informational Sciences 17 (2), $235-250$.

[6] Byington CS, Roemer MJ, Kacprzynski GJ and Galie T. Prognostic enhancements to diagnostic systems for improved condition-based maintenance, in IEEE Aerospace Conference, 916 March 2002, Big Sky, Montana. p. 111, IEEE, New York.

[7] Castanier, B., Bérenguer, C., Grall, A., 2003. A sequential condition-based repair/replacement policy with non-periodic inspections for a system subject to continuous wear. Applied Stochastic Models Business and Industry. 19 (4), 327-347.

[8] Cox, D., 1972. Regression models and life-tables. Journal of the Royal Statistical Society. Series B (Methodological) 34 (2), 187-220.

[9] Deloux, E. ,Castanier, B. ,Bérenguer, C., 2009. Predictive maintenance policy for a gradually deteriorating system subject to stress. Reliability Engineering \& System Safety 94 (2),418-431.

[10] Deloux, E., Castanier, B., Bérenguer, C., 2009. An adaptive condition-based maintenance policy with environmental factors. Risk and Decision Analysis in Maintenance Optimization and Flood Management, IOS Press, Kallen, M.J. and Kuniewski, S.P.137-148,

[11] Deloux, E., Fouladirad, M., Bérenguer, C., 2011. Condition-based maintenance strategies for a partially observable deteriorating system. Proceedings of ESREL 2011, Troyes, France 19-23 september.

[12] Dieulle, L., Bérenguer, C., Grall, A., Roussignol, M., 2003. Sequential condition-based maintenance scheduling for a deteriorating system. European Journal of Operational Research 150 (2), 451-461.

[13] Fraser KF. An overview of health and usage monitoring systems (HUMS) for military helicopters, 1994, Defence Science and Technology Organisation: Melbourne. p. 24.

[14] Grall, A., Bérenguer, C., Dieulle, L., 2002. Continuous-Time Predictive-Maintenance Scheduling for a Deteriorating System. IEEE Transactions on Reliability 51 (2), 141-150.

[15] Hunt SR and Hebden IG. Validation of the Eurofighter Typhoon structural health and usage monitoring system. Smart Materials and Structures, 2001. 10: p. 497503. 
[16] Kalgren PW, Baybutt M, Ginart A, Minella C, Roemer MJ and Dabney T. Application of prognostic health management in digital electronic systems, in IEEE Aerospace Conference, 10 March 2007, Big Sky, Montana, p. 18, IEEE, New York.

[17] Kharoufeh, J.P. Explicit results for wear processes in a Markovian environment Operation Research Letters 31(3) (2003) 237-244.

[18] Le Son, K. and Fouladirad, M. and Barros, A. and Levrat, E. and Iung, B. Remaining useful life estimation based on stochastic deterioration models: a comparative study Journal, Reliability Engineering and Systems Safety 2013, vol 112.

[19] Lawless, J., Crowder, M., 2004. Covariates and random effects in a gamma process model with application to degradation and failure. Lifetime Data Analysis 10 (3), 213-227.

[20] Makis, V., Jardine, A., 1992. Optimal replacement in the proportional hazards model. INFOR 30 (1), $172-183$.

[21] Molent, L. A unified approach to fatigue usage monitoring of fighter aircraft based on F/A-18 experience, in Congress of the International Council of the Aeronautical Sciences (ICAS98), 1318 September 1998, Melbourne, p. 111. ICAS, Bonn, Germany.

[22] Orsagh R, Roemer MJ, Sheldon J and Klenke CJ. A comprehensive prognostic approach for predicting gas turbine engine bearing life, in ASME Turbo Expo, 1417 June 2004,Vienna. p. 19, ASME, New York.

[23] Orsagh R, Brown D, Roemer MJ, Dabney T and Hess A. Prognostic health management for avionics system power supplies, in IEEE Aerospace Conference, 512 March 2005, Big Sky,Montana. p. 17, IEEE, New York.

[24] Orsagh RJ, Sheldon MJ, Roemer and Klenke CJ. Prognostics / diagnostics for gas turbine engine bearings, in IEEE Aerospace Conference, 512 March 2005, Big Sky, Montana. p. 19, IEEE, New York.

[25] Park, K. S., 1988. Optimal continuous-wear limit replacement under periodic inspections. IEEE Transactions on Reliability 37 (1), 97-102. 
[26] Roemer MJ, Byington CS, Kacprzynski GJ and Vachtsevanos G. An overview of selected prognostic technologies with application to engine health management, in ASME Turbo Expo, 811 May 2006, Barcelona, Spain. p. 19, ASME: New York.

[27] Singpurwalla, N. D., 1995. Survival in dynamic environnements. Statistical Science 1 (10), 86-103.

[28] Tinga T. Application of physical failure models to enable usage and load based maintenance. Reliability Engineering and System Safety, 2010. 95(10): p. 10611075.

[29] Tinga T,Janssen R. The interplay between deployment and optimal maintenance intervals for complex multi-component systems Proceedings of the Institution of Mechanical Engineers, Part O: Journal of Risk and Reliability June 2013 vol. 227 no. 3 227-240

[30] van Noortwijk, J. M., 2009. A survey of the application of gamma processes in maintenance. Reliability Engineering and System Safety 94 (1), 2-21.

[31] Wang, H., 2002. A survey of maintenance policies of deteriorating systems. European Journal of Operational Research 139 (3), 469-489.

[32] Watson M, Byington CS, Edwards D and Amin S. Dynamic modeling and wear-based remaining useful life prediction of high power clutch systems, in ASME/STLE International Joint Tribology Conference, 2427 October 2004, Long Beach, USA. p. 112,

[33] Wubben JPC, Tinga T and Wortmann JC. Dynamic maintenance based on system usage profiles. Submitted to Journal of Quality inMaintenance Engineering, 2013: p. 115.

[34] Zhao, X., Fouladirad, M., Bérenguer, C., 2010. Condition-based inspection/replacement policies for non-monotone deteriorating systems with environmental covariates. Reliability Engineering and System Safety 95 (8), 921-934. 